
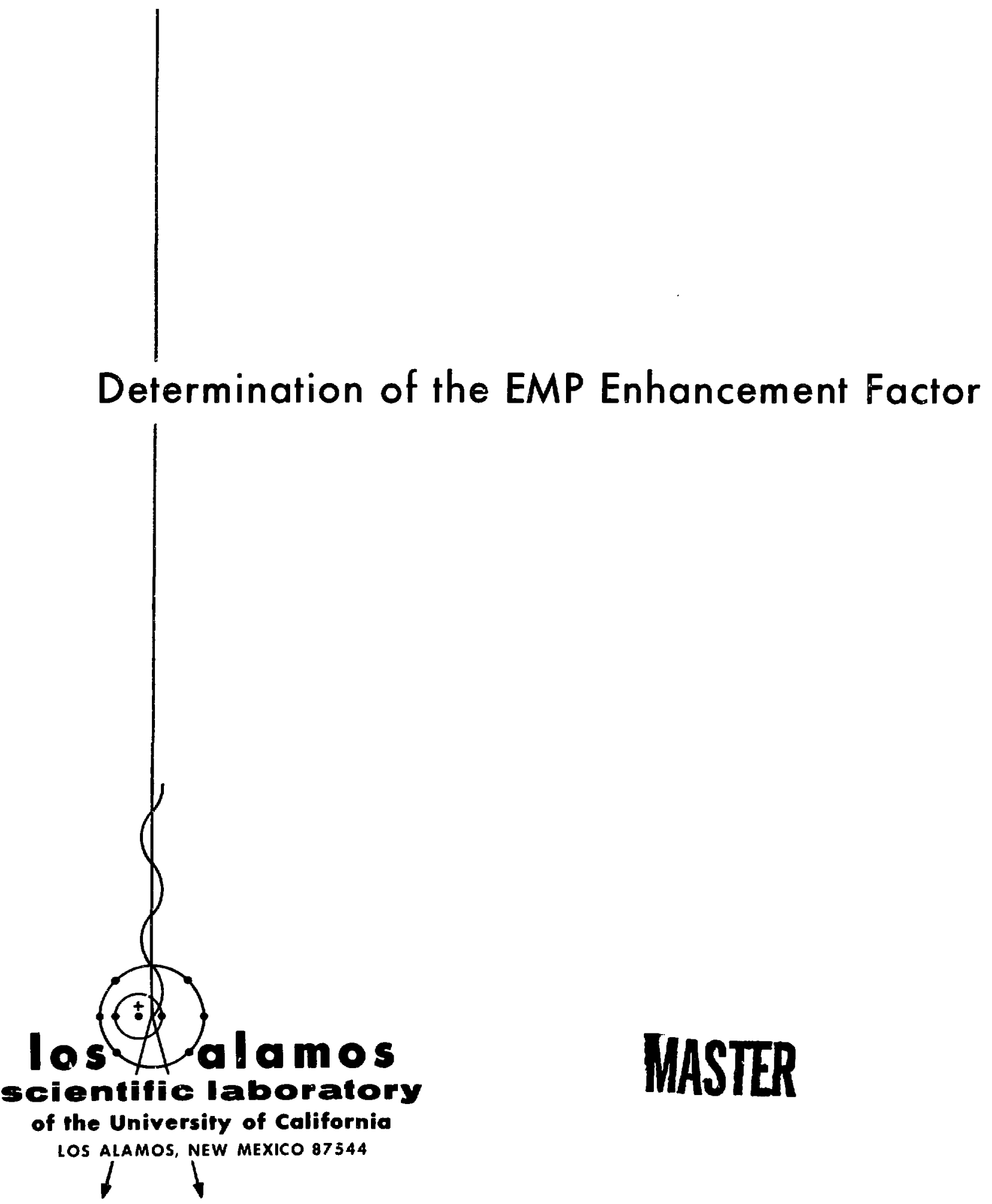
This report was prepared as an account of work sponsored by the United States Government. Neither the United States not the United States Aiomic Energy Commission, nor any of their employees, nor any of their contrac. tors, subcontractors, or their employees, makes any warranty, express or im. plied, or assumes any legal liability or responsibility for the aceuraey, com. pleteness or usefulness of any information, apparatus, product or process dis. closed, or represents that its use would not infringe privately owned rights.

Printed in the United Sistes of America. Availathe trom National Technical Inlormation Servies

U. S. Dethimen or Camnares

5285 Poit Rovall Rost

Springfintet, Virginia 2215

Price: Ptimed Copy S900: Mictotiche $\mathbf{5 0 . 9 5}$

24 . 


\section{Determination of the EMP Enhancement Factor}

by

C. U. Benton

A. N. Phillips

R. W. Buchenen"

H. M. Fowles"

- Present Address: Denver Resuarch Institute

Denver, Colorado

Norice

Thin sepont wh perpured an an account of work

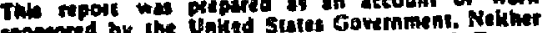
apacored oy the Unked Sidied Sinte Atonic Eatisy

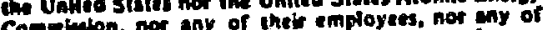
Com minch.

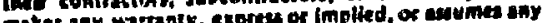
mines ony watrany. expres or for the securecy. eom.

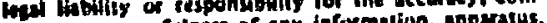

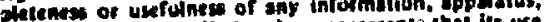
waduel of gocess alcelosed, or teptesents thet its use would rol infriage prirately owned rights.

\section{University of Denver}

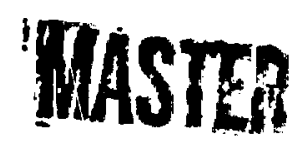




\title{
DETERMINATION OF THE EMP ENHANCEMENT FACTOR
}

\section{By}

\author{
C. U. Benton, A. N. Phillips,
}

R. W. Buchanan, and H. M. Fowles

\begin{abstract}
EMP signals recorded aboard a C-135 aircraft are discussed with respect to the difference in amplitude and phase characteristics from that of a free-space signal. The enhancement factor is defined as the ratio of the normalized amplitude of the aircraft signal to the normalized amplitude of close-in sensors for a 2 MV pulsed antenna system. Three different close-in sensors were used to measure fields in excess of $10 \mathrm{kV} / \mathrm{m}$. The radiation pattern was mapped in aximuth and elevation by the aircraft and the close-in sensors. The enhancement factor and the time rate of change of the EMP signal is seen to vary significantly with aircraft attitude and position.
\end{abstract}

\section{INTRODUCTION}

EMP-type signals recorded aboard aircraft differ from the free-space signal in amplitude and phase. In general, the amplitude of the EMP signal is greater than the free-space signal and a time or phase variation is seen over at least the first $100 \mathrm{~ns}$ or so when compared to a free-space signal.

Two wideband EMP sensor systems were calibrated in the Los Alamos Scientific Laboratory (LASL) parallel plate transmission line facility. The $\bar{E}$ field in this facility is known to within 1\%. One system was installed on top of a C-135 aircraft at station 1070, and another on the bottom of the aircraft at station 1310 .

The 2-Mv pulsed antenna system of the Denver Research Institute (DRI) was installed in Hawaii. The radiated field was mapped using the DRI sphere sensor to determine the lobe bearing between $210^{\circ}$ through $340^{\circ}$ true from the pulser in azimuth, and from $1^{\circ}$ to $52^{\circ}$ in nlevation. Twe flights of the aircraft were made through the mapped portion of the radiated lobe. ${ }^{12}$ Three close-in sensors in fixed locations simultaneously recorded the series of pulses observed by the aircraft for these flights.

Cross calibration of the two aircraft and the thries ciose-in sensors was performed at the LASL. facility after the operation. Analysis of the data in the time and frequency domains gave enhancement factors $\left(E_{f}\right)$ that varied from 1.76 to 2.96 for the aircraft's bottom antenna (BA), and from 1.12 to 2.53 for the top antenna (AD). For the time from the first positive peak of the signal, the BA time varied from 30.3 to $49.3 \mathrm{~ns}$, the AD time varied from 18.9 to $34.9 \mathrm{~ns}$, compared to the DRI close-in sphere sensor time of $34.5 \mathrm{~ns} \pm 2 \%$. Plots of $\mathrm{E}_{\mathrm{f}}$ vs bearing of the pulser from the aircraft, and $E_{f} v s$ depression angle of the pulser from the aircraft, indicate the dependence of $E_{f}$ on the direction of arrival of the EMP ray. A relationship between the time or phase anomaly to the elevation angle is also seen.

\section{THE RMP SIMULATOR}

The DRI pulsed antenna system (EMP simulator) ${ }^{3}$ used to provide the source test function is a Marx generator, biconic antenna combination operated in the vertical mode. The Marx generator consists of $320.01 \mu \mathrm{F}$ capacitors charged to a potential of $45 \mathrm{kV}$. These are then discharged into the antenna in series giving a source voltage at the antenna of $1.44 \mathrm{MV}$. 
For purposes of this experiment, a vertically polarized signal was required. Further, ideally the signal should be uniform in azimuth and elevation profiles. Thus, a vertical monopole antenna is a better radiator than the biconic antenna. The simulator was modified before the experiment to eliminate as much of the lower bicone as possible. Ideally, the feed-point, which is a pressurized spark gap, would be composed of the radiating antenna element and a flat ground plane. Because of the main gap configuration, this was not completely realizable. However, the major portion of the bottom cone was removed and a ground plane installed, which left an effective bottom cone of about 12 in.

The simulator was installed in a 24-in.-deep pit which allowed the addition of an essentially flat ground plane in the immediate vicinity. Thic simulator modification and installation were important factors in the generation of a radiation pattern that was well behaved both in azimuth and elevation.

The simulator was installed at Lat. $21^{\circ} 19^{\prime} 50.8^{\prime \prime}$ and Long. $157^{\circ} 57^{\prime} 06^{\prime \prime}$. The installation site was composed of crushed coral at an elevation of about $2 \mathrm{ft}$ above mean sea level. A ground plane was installed from an azimuth of $210^{\circ} \mathrm{T}$ to $340^{\circ} \mathrm{T}$. The ground plane consisted of No. 8 aluminum wires at $3^{\circ}$ increments and nominally $100 \mathrm{ft}$ in length. The ground plane was extended to $160 \mathrm{ft}$ in length from $230^{\circ} \mathrm{T}$ to $242^{\circ} \mathrm{T}$ to carry over a drainage ditch. This was an important sector since it extended in the direction of the DRI sphere sensor. The ground plane and pattern radiated in azimuth is shown in Fig. 1.

Three types of sensors were used to monitor the simulator output for control and field mapping. The first was a LASL parallel plate E-field sensor which was located on

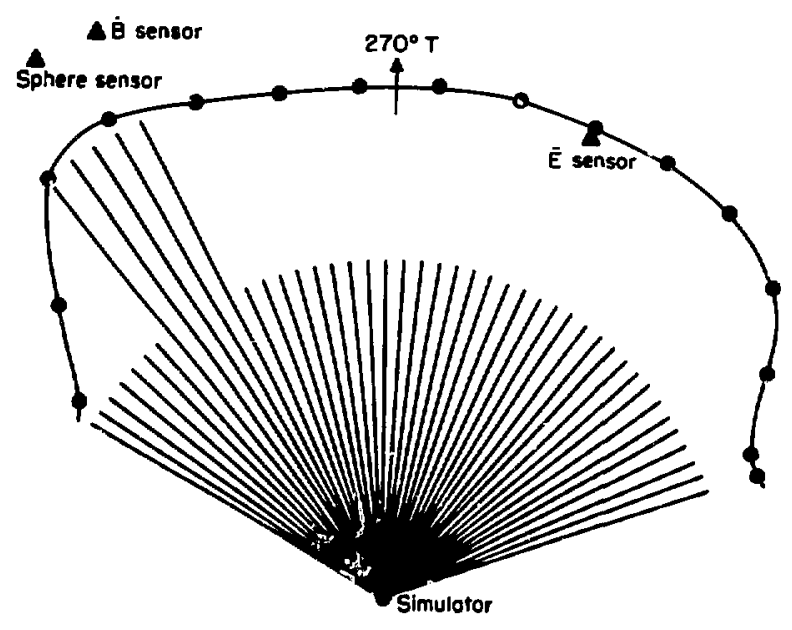

Fig. 1

Ground plane and azimutb field. the $292^{\circ}$ azimuth at an elevation angle of $9.624^{\circ}$ and at a slant distance of $47.188 \mathrm{~m}$ from the simulator.

The second sensor was a $B$ loop located on the $242^{\circ}$ azimuth at an elevation angle of $1.468^{\circ}$ and at a slant distance of $72.573 \mathrm{~m}$ from the simulator.

The third sensor was the DRI sphere located on the $236^{\circ}$ azimuth at an elevation angle of $8.726^{\circ}$ and at a. slant distance of $75.12 \mathrm{~m}$ from the simulator. The sphere sensor is self-contained, presents the smallest possible distortion of the $\bar{E}$ field, and is easily moved from position to position; thus, it was used for field mapping and cross-correlation of the other sensors.

The azimuthal field mapping was done using the sphere mounted on a forklift. It was recognized at the time that the forklift would prevent precise measurements after the first $10 \mathrm{~ns}$; however, the peak field could be determined with confidence. The sensor antenna load gap was a nominal $22 \mathrm{ft} 10 \mathrm{in}$. above the ground and the distance from the simulator was $100 \mathrm{ft}$, except for the points at $230^{\circ} \mathrm{T}$ and $239^{\circ} \mathrm{T}$ where the distance was $160 \mathrm{ft}$. Measurements were made at 14 points in $9^{\circ}$ azimuthal increments from $212^{\mathrm{C}} \mathrm{T}$ to $332^{\circ} \mathrm{T}$. The $\dot{\mathrm{B}}$ loop was used as control and two signals were recorded at exch point.

The elevation radiation pattern was mapped using the sphere and the same $\dot{B}$ control. The sphere was supported by a crane with a 70-ft boom at a radial distance of $15.24 \mathrm{~m}$ from the simulator. Two measurements were made at $5^{\circ}$ increments from $5^{\circ}$ to $50^{\circ}$ and a final reading was made at $52^{\circ}$. The radiated pattern in elevation should be a cosine function. Figure 2 shows the theoretical and measured radiation pattern in elevation.

\section{CLOSE-IN SENSORS}

The $\dot{B}$ sensor used was the standard model MGL $2 A$ manufactured by EG\&G. Its output was recorded on 35-mm film from a HP-183 oscilloscope.

The parallel plate $\vec{E}$-field sensor was built by LASL for this experiment. It consists of two small circular parallel plates approximately 5 in. in diameter and separated by

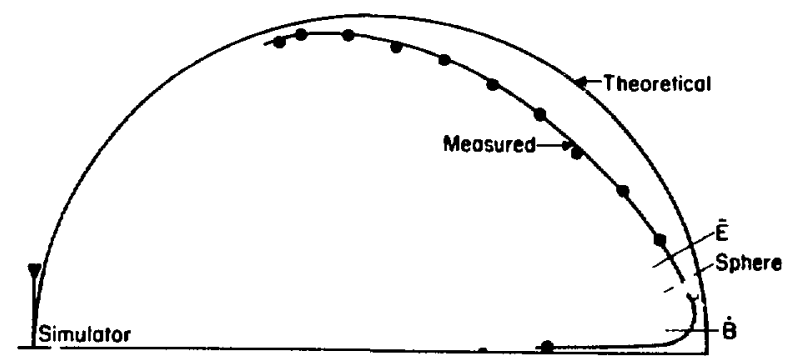

Fig. 2

Vertical field. 
about 1 in. Between the plates are installed $500 \mathrm{MHz}$ bandwidth amplifiers. Shielded leads carry the total output signal and input power $27 \mathrm{ft}$ away and in the direct line-of-sight from the simulator.

The DRI sphere is a complete instrument package contained within a 25 -in.-diam spherical shell. A radially mounted stub antenna serves as the electric field sensor.

The sensor was designed to occupy as small a volume as possible and have a simple geometrical shape so that any field distortion caused by the sensor could be readily calculated and accounted for. Other design criteria followed were electrical shielding of the recording instrumentation from the intense fields being measured and construction of the system as a light-weight self-contained unit suitable for use in field-mapping experiments. These considerations led to the present design which uses a 6 in. radial stub antenna mounted on an aluminum sphere 25 in. in diameter. The recording instrumentation includes an oscilloscope, a 35-mm camera, and a battery power source, all of which are contained within the spherical shell. The total weight of the instrument is $50 \mathrm{lb}$.

When exposed to an incident plane-wave $E_{0}$, the radial electric field at the surface of the sphere is given by ${ }^{4}$

$$
E_{r}=\frac{-E_{0} \cos \theta}{(k a)^{2}} \sum_{n=1}^{\infty} j^{-n}(2 n+1) \frac{P_{n}^{\prime}(\cos \theta)}{h_{n}{ }^{(2)}(k a)+(k a) h_{n}{ }^{(2)^{\prime}}(k a)},
$$

where $h_{n}{ }^{(2)}(k a)$ is the spherical Hankel function and the prime denotes its derivative with respect to its argument; $P_{n}{ }^{\prime}(\cos \theta)$ is the Associated Legendre Polynomial; $k$ is the free space propagation constant $(k=2 \pi / \lambda)$; and $a$ is the radius of the sphere. The geometry is shown in Fig. 3 with the direction of wave propagation along the $z$ axis and the electric field in the $x$ direction. With the stub antenna located at $r=a, \theta=\pi / 2, \phi=0$, the angle $\phi=\pi / 2-\theta$ corresponds to the elevation angle measured from the sphere to the source point. For $\mathrm{ka}<1$, Eq. (1) reduces to the static field solution

$$
E(r)=1+\frac{2 a^{3}}{r^{3}} E_{0} \cos \theta
$$

\section{evaluated at $r=a$.}

The magnitude $\left|E / E_{0}\right|$ from Eq. (1) is plotted in Fig. 4 as a function of elevation angle for frequencies between 20 and $100 \mathrm{MHz}$. The static field solution is included for comparison. The curves show the static field solution to be within $10 \%$ of the full solution for frequencies below approximately $80 \mathrm{MHz}$ at elevation angles between $+6^{\circ}$ and $-30^{\circ}$.

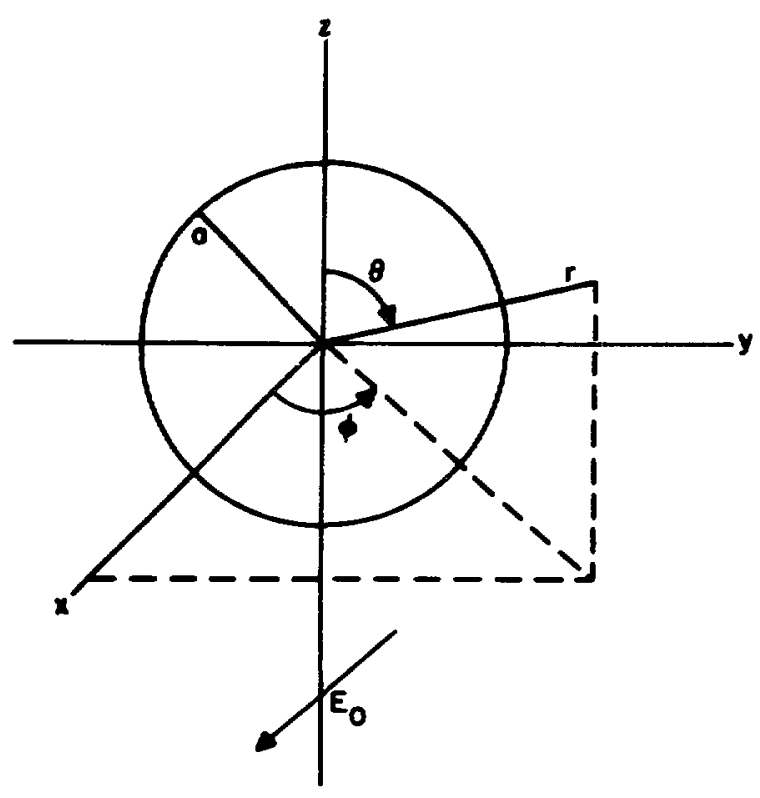

Fig. 3

Geometry of spbere.

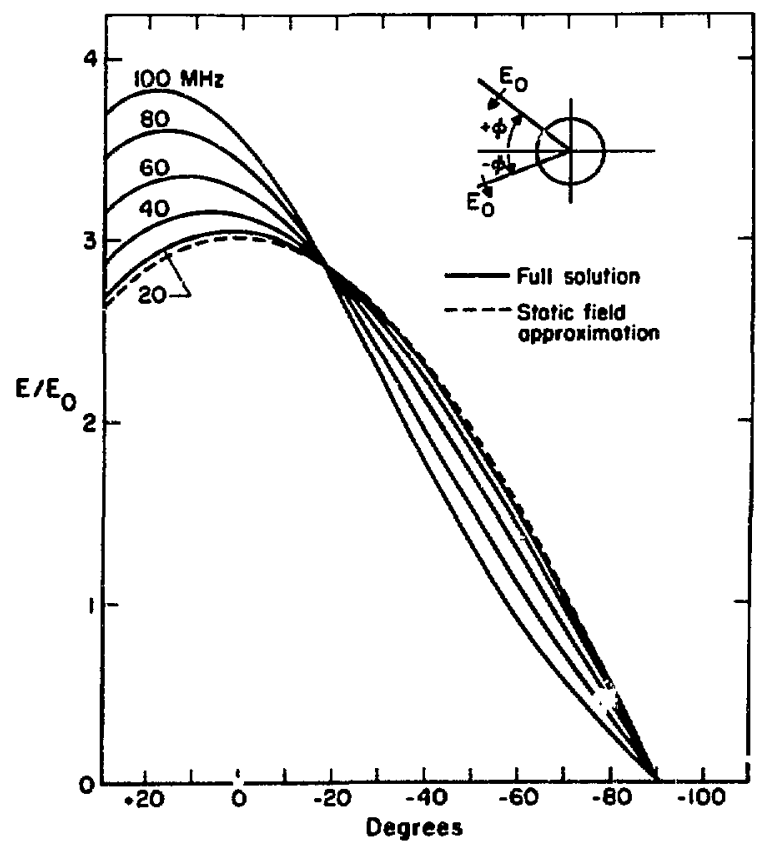

rig 4

Radiation pattem of a dipole on a sphere. 
The effective height of the stub antenna of length $L$ is given by the integral

$$
h_{e}=\frac{1}{I_{0}} \int_{a}^{a+L} 1(r) \times E(r) d r
$$

Using the static field solution for $E(r)$ and a linear current distribution for $\mathrm{I}(\mathrm{r})$ gives

$$
h_{e}=\frac{L}{2}\left(1+\frac{2}{1+L / a}\right)
$$

for the effective height of a short probe mounted on a spherical surface. Since $L / 2$ is the effective height of a short probe mounted on a flat ground plane, the quantity in parenthesis can be interpreted as a curvature factor which accounts for the increase of the radial electric field near the curved surface of the sphere. With $L=6$ in. and $a=12.5$ in., the antenna effective height and curvature factor are $0.18 \mathrm{~m}$ and 2.35 , respectively.

The antenna equivalent circuit is shown in Fig. 5 . The antenna and load impedances $Z_{A}$ and $Z_{B}$ form a voltage divider which reduces the sensor sensitivity by an amount $Z_{A} /\left(Z_{A}+Z_{B}\right)$. The resultant sensitivity in volts per volt/ meter is then

$$
V_{L} / E=h_{e} Z_{A} /\left(Z_{A}+Z_{B}\right)
$$

In practice, the impedances $Z_{A}$ and $Z_{B}$ are capacitive and can be measured separately. However, to eliminate possible errors that mutht occur in the separate determination of $Z_{A}$ and $Z_{B}$, the sensor was calibrated experimentally. Measurements were made on a $1 / 4$ scale model of the sphere using the parallel plate transmission line facility at LASL. The facility produces a uniform field that is known to an accuracy of $1 \%$. The resultant sensitivity of the sensor was found to be $7.5 \times 10^{-4} \mathrm{~V}$ per $\mathrm{V} / \mathrm{m}$ when loaded with a 100:1 scope probe (Tektronix Model P6009).

The transmission line facility was also used to verify the curvature factor. Measurements were made with the

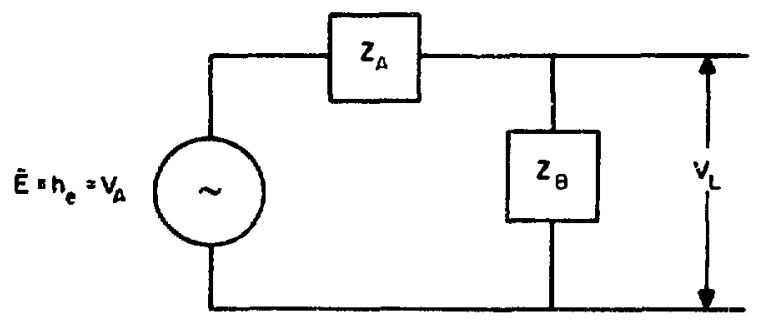

Fig. 5

Antema equivalent circuit. 1/4-scale probe mounted on a flat ground plane and on a 6-in.-diam sphere. The measured curvature factor was found to be 2.42 , in good agreement with the calculated value of 2.35 . The results verify that the assumptions made in deriving Eq. (4), i.e., a linear current distribution and use of the static rather than the full-field solution, are valid assumptions.

\section{DATA ANALYSIS}

A printout of aircraft position and attitude was made at 5 -sec intervals during the time pulses were transmitted from the simulator. World time to the nearest second was simultaneously recorded with the position data. The slant range, azimuth, and depression angle was manually recorded at pulse time from a precision radar. World time was also recorded on the $35-\mathrm{mm}$ film for both BA sensors and the $A D$ sensor.

Assuming film speed to be constant, actual pulse time was measured to the nearest millisecond. The position and attitude of the aircraft was then linearly interpolated for the actual pulse time. The slant range from the precision radar was undoubtedly more accurate than the position information from the inertial guidance system (INS). The radar information was manually recorded while the INS information was automatically recorded at precise incervais. A graphic analysis of aircraft position with respect to time demonstrated that INS position was more reliable for individual readings. Since the INS is subject to drift, the precision radar information will be automatically recorded and used in future experiments of this type.

Close-in sensor information was identified by pulse number and clock time. Aircraft sensor information was identified by digital time on the edge of the film. After the film was processed, it was readily marked by pulse number. The data pulses, with time and amplitude calibrations, were read and ca:ds punched in microns vs microns. For the data pulses, the cards also contained tags to indicate the beginning and the top of the first peaks to facilitate rapid calculations of the peak amplitudes.

Volts us time for the data pulses was obtained by linear interpolation of the calibration data. Amplitudes for the pulses were calculated in volts/meter and, using the slant range, were calculated in volts/meter at $1 \mathrm{~km}$.

To obtain graphs in the frequency domain, a fast Fourier transform for real data, written by B. R. Hunt of LASL, based on the method of Singieton, ${ }^{5}$ was used.

Amplitudes of the aircraft data were multiplied by the ratio of the first-peak amplitude of the aircraft sensor to the first-peak amplitude of the sphere sensor. The aircraft traces were then subtracted from the sphere traces to obtain the residue, which was plotted in both the time and frequency domain. 


\section{RESULTS}

Discounting aircraft refiections, particularly those from the wing tips, ${ }^{6,7}$ the difference in time between the first maximum positive peak and the maximum negative peak was seen to be significantly longer for the BA and shorter for the AD than that measured for the close-in sensors. This is assumed to be caused by the phasedistortion of the free-space field by the aircraft structure. This distortion could be cosine-related to the free-space field. It was found that the BA time multiplied by the lobe correction, and the $\mathrm{AD}$ time divided by the lobe correction, gave a value very close to that of the DRI sphere. The reason for this may be coincidental, but it is believed to have some physical relationship, unexplained at this time. Some of this effect could be propagation delay in the atmosphere although it does not appear to agree well with published information, for example, Levine (1970). ${ }^{8}$ of the 55 pulses studied, pulse 15 of $10 / 24 / 72$ is used as a typical example. Time and frequency domain plots are shown as Figs. 6 through 17 after all the corrections above had been applied.

The enhancement factor $\left(E_{f}\right)$ on effective antenna and sensor system gain was then calculated by dividing the first maximum normalized and corrected peak on the aircraft by the value of the normalized and corrected same peak from the sphere sensor. This was then examined with respect to the depression angle of the simulator from the aircraft, the azimuth angle of the simulator from the aircraft, and the elevation angle of the

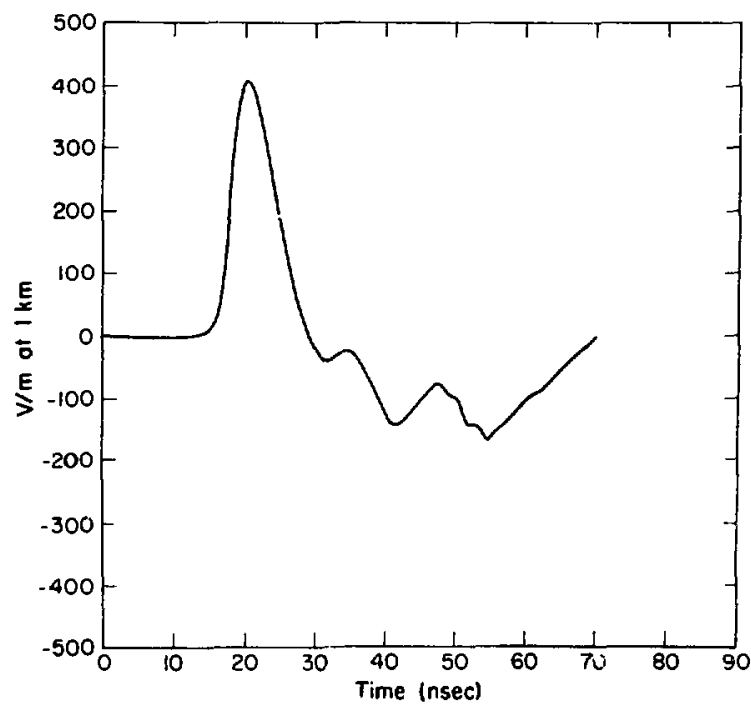

Fig. 6

Sphere sensor. Trace 15 of $10 / 24 / 72$.

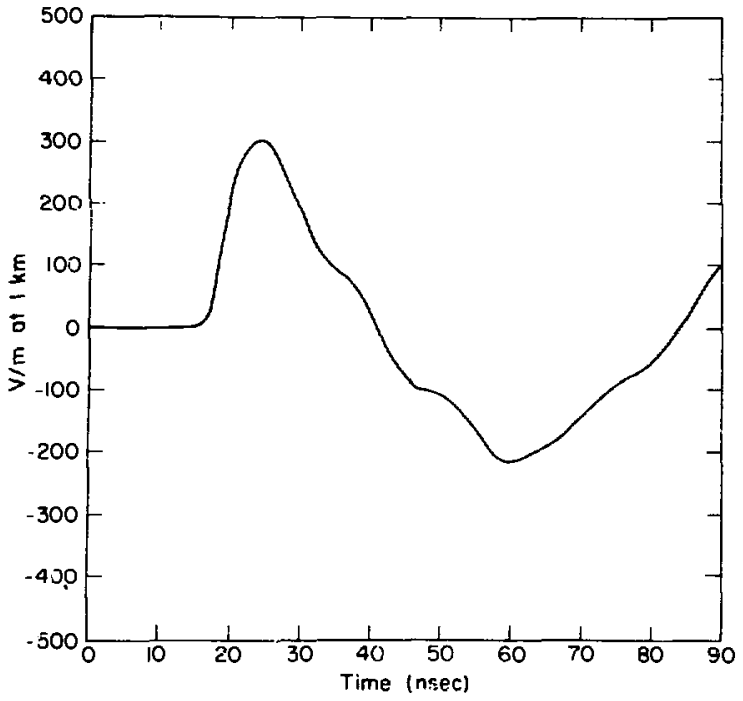

Fig. 7

B seissor. Trace 15 of $10 / 24 / 72$.

aircraft from the simulator. These relationships are plotted in Figs. 18 through 28 . Some variational trend can be seen, particularly when the ray path passes near the wing tip. If the azimuth angle is limited to $\pm 2 \%$ tiom the beam, and the depression angle from $8^{\circ}$ to $12^{\circ}$, then the $E_{f}$ for the $B A$ is $2.18 \pm 13 \%$ and for the $A D$ is $1.28 \pm 14 \%$. No correlation between roll angle and $E_{f}$ was

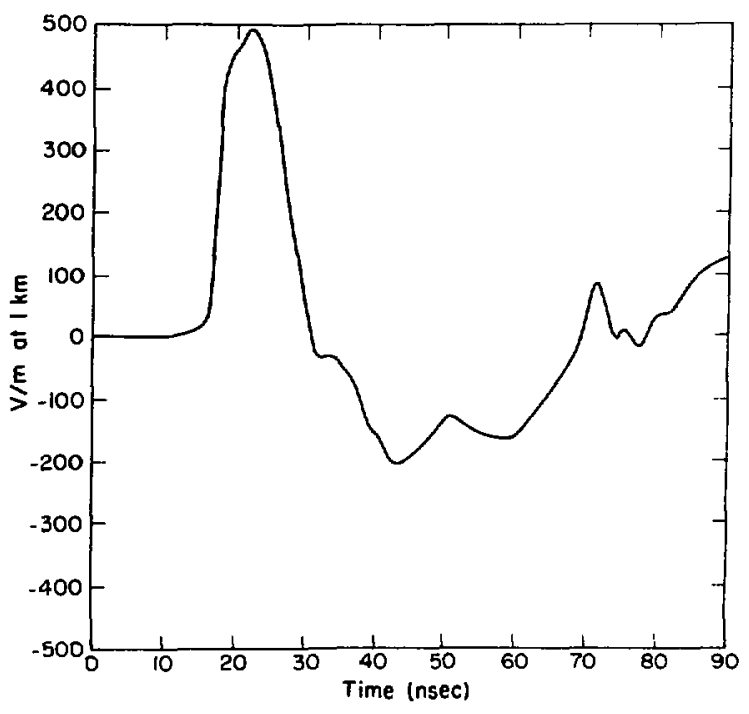

Fig. 8

$\bar{E}$ sensor. Trace 15 of $10 / 24 / 72$. 


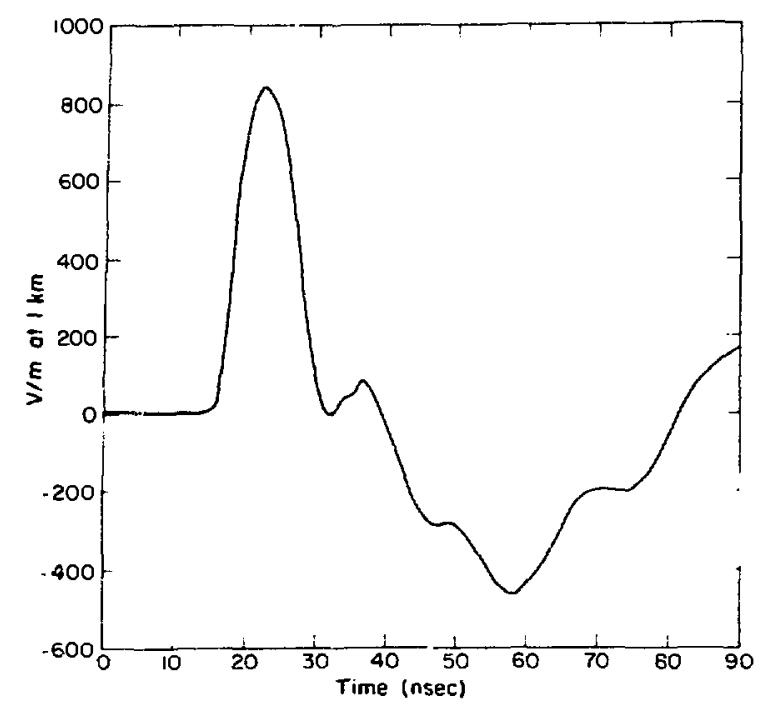

Fig. 9

BA sensor scope 1. Trace 15 of 10/24/72.

observed. Table 1 lists $E_{f}$ for the average corrected reading from the $B A$, and for the $A D$ vs azimuth and depression angles for 29 pulses.

\section{CONCLUSIONS}

For any type of EMP sensor on any type of aircraft, there exists in enhancemen. factor which shows significant variation in time and ainplitude from that of the free

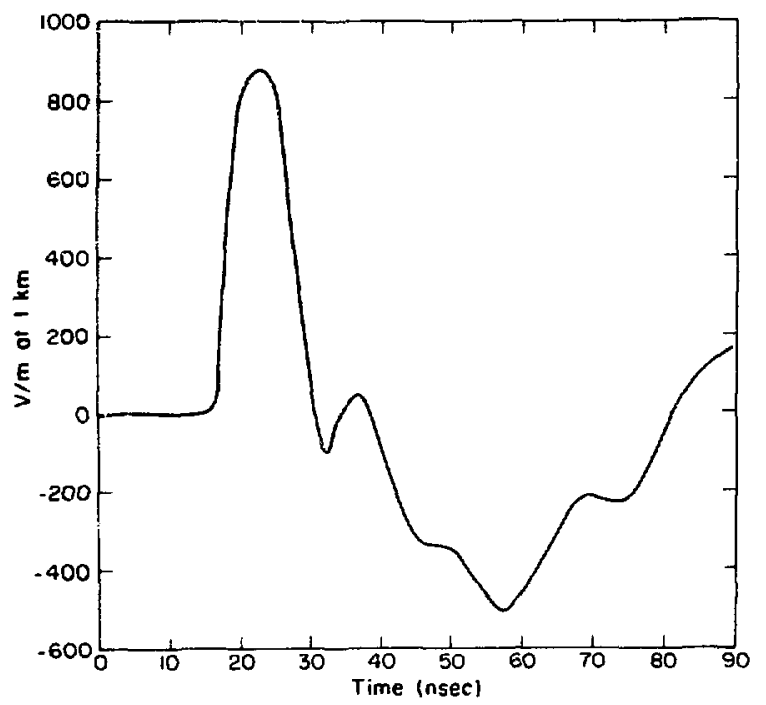

Fig. 10

BA sensor scope 2. Trace 15 of 10/24/72.

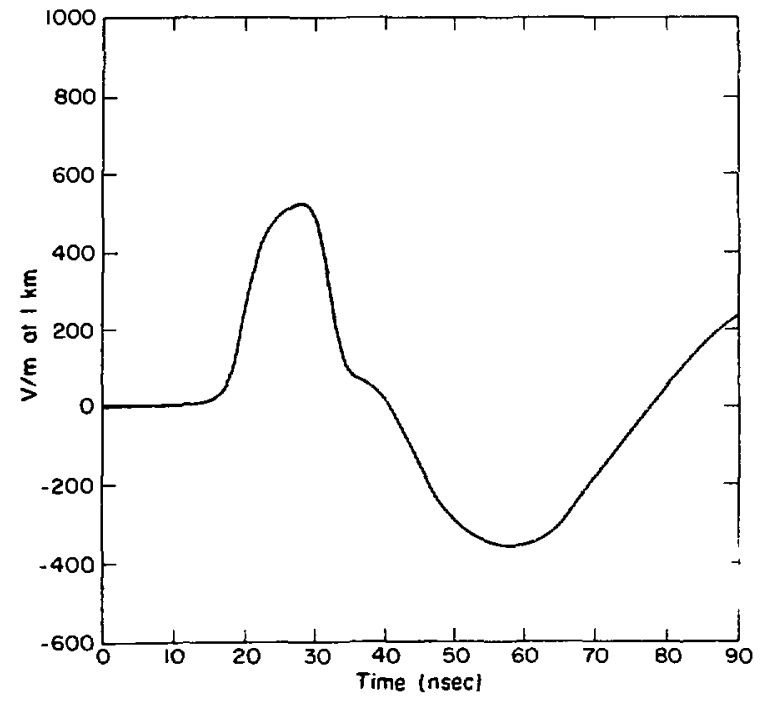

Fig. 11

$A D$ sensor. Trace 15 of $10 / 24 / 72$.

space field. For any specific system, a factor of three or so may be measured over a relatively small variation of azimuth and depression angles. Because of the geometry of an individual aircraft, the location of an EMP sensor on the aircraft, and the charge distribution on the aircraft due to an EMP signal, it is difficult if not impossible to

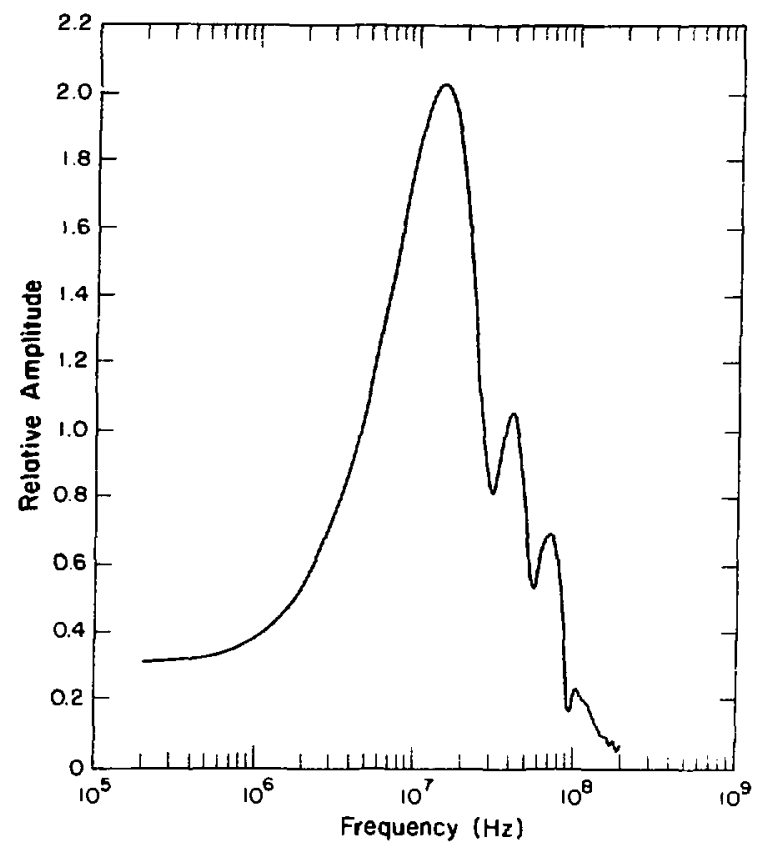

Fig. 12

Spbere sensor. Trace 15 of 10/24/72. 


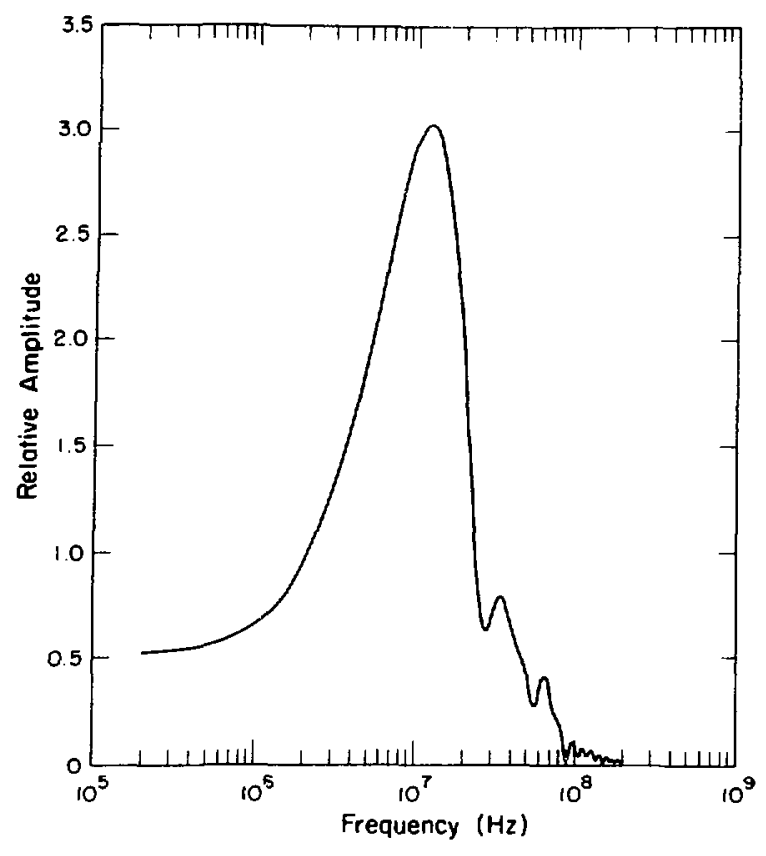

Fig. 13

$\dot{B}$ sensor. Trace 15 of 10/24/72.

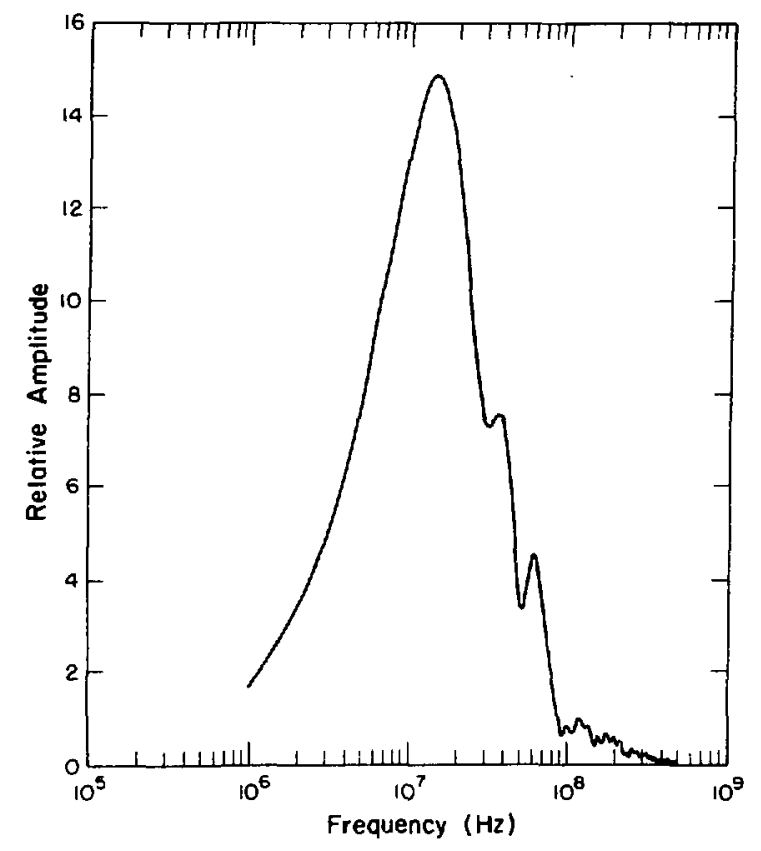

Fig. 14

$\bar{E}$ sensor. Trace 15 of 10/24/72.

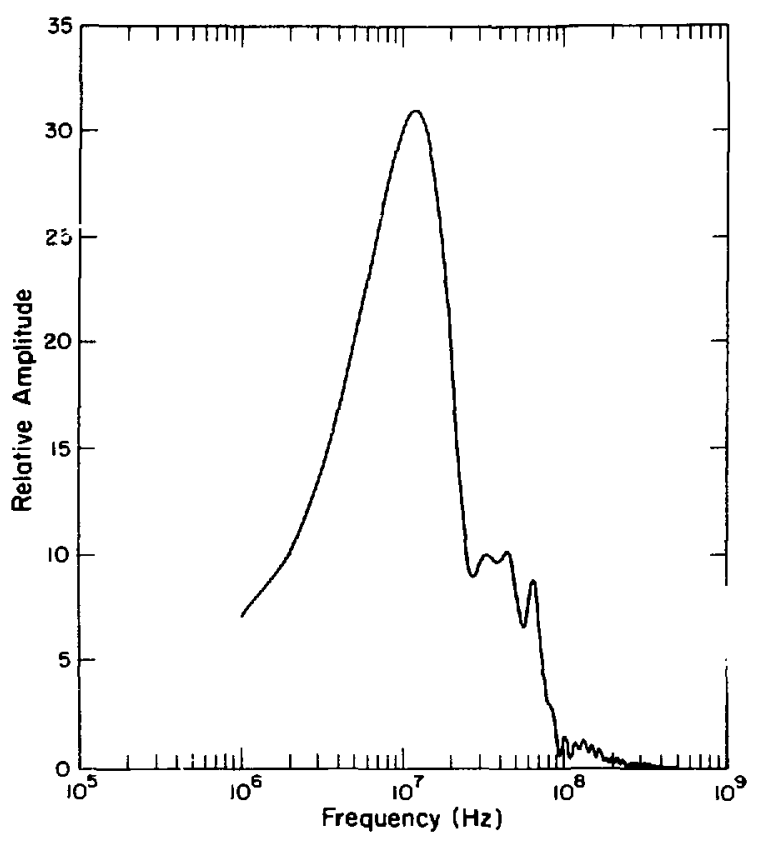

Fig. 15

$B A$ sensor scope 1. Trace 15 of 10/24/72.

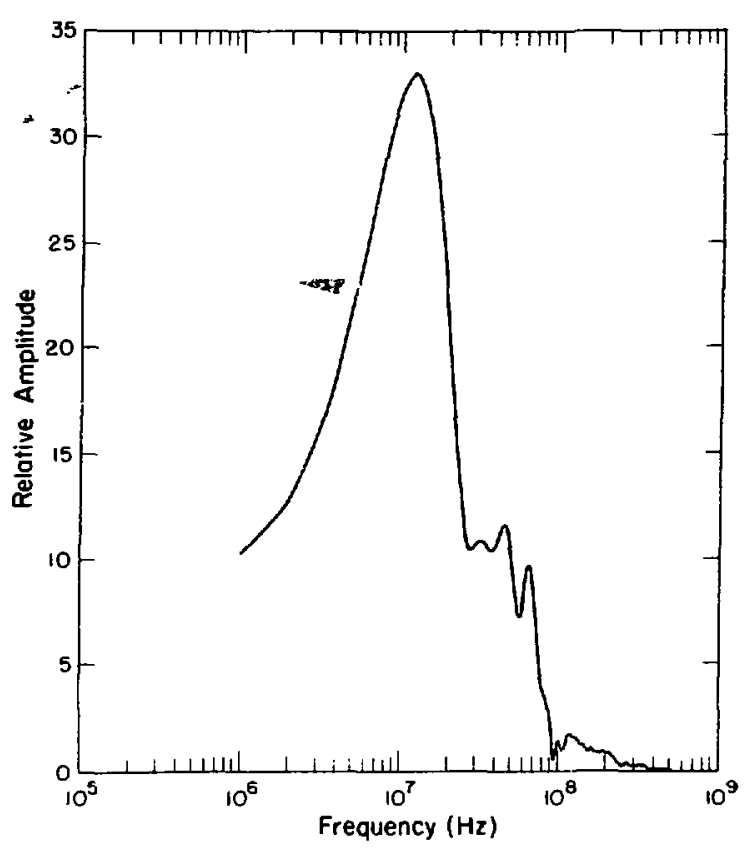

Fig. 16

$B A$ sensor scope 2. Trace 15 of 10/24/72. 


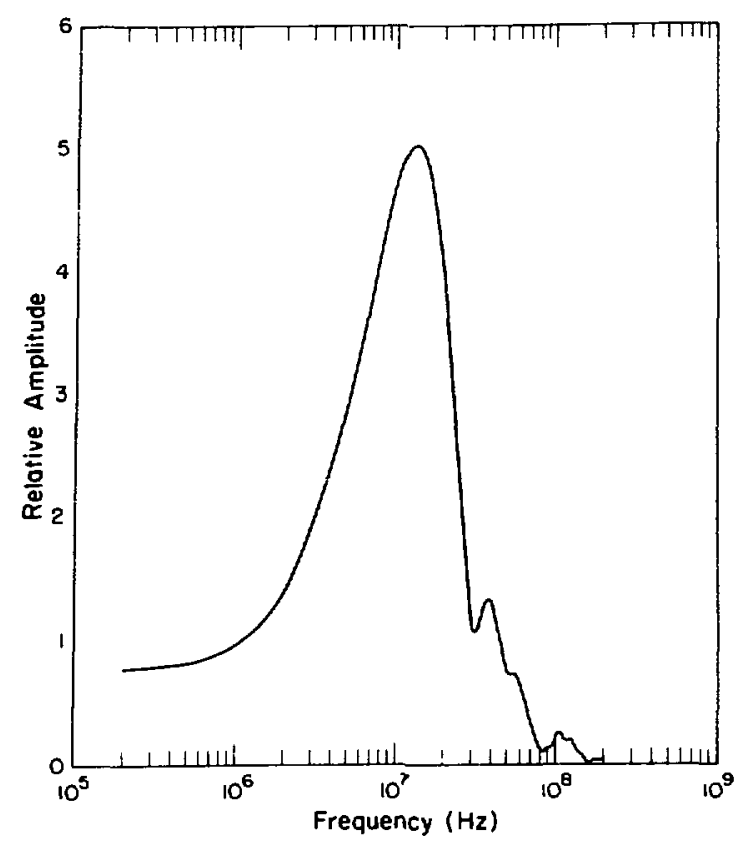

Fig. 17

AD sensor. Trace 15 of 10/24/72.

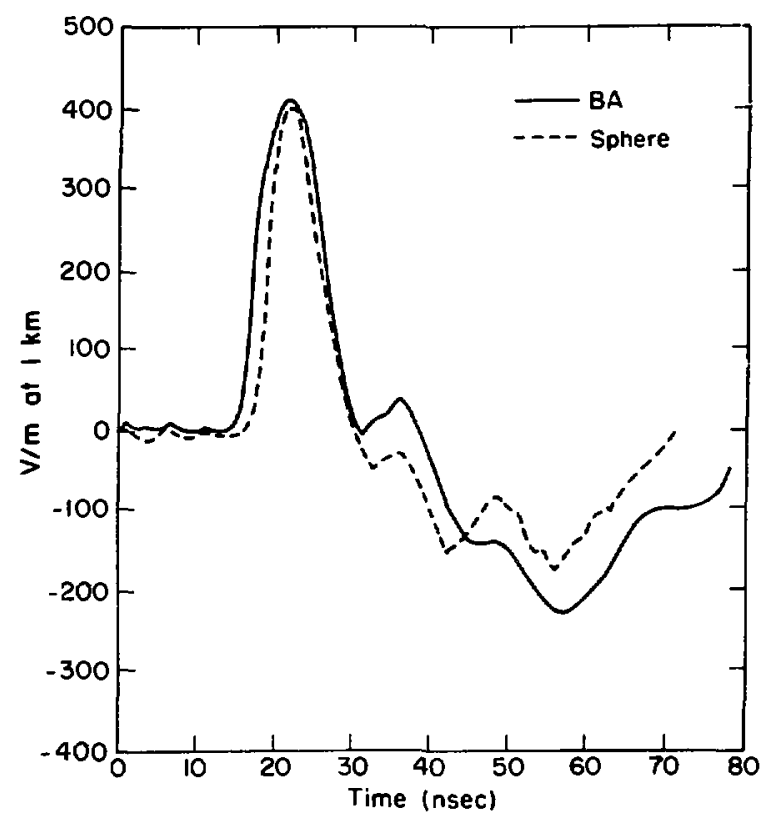

Fig. 18

Sphere and $B A$ sensors, lobe and $E_{f}$ corrected. Trace 15 of 10/24/72.

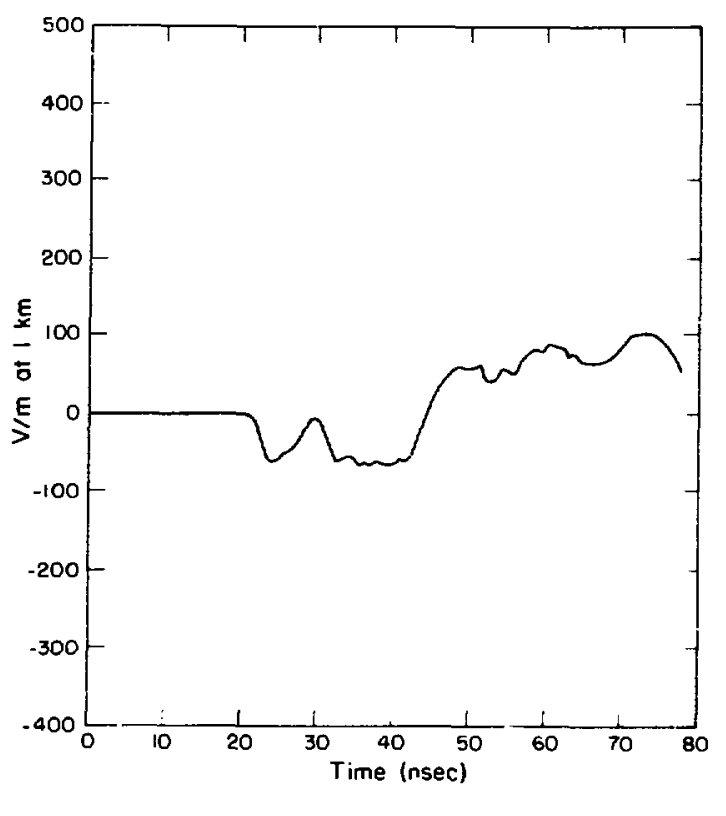

Fig. 19

Spbere sensor minus $B A$ sensor, lobe and $E_{f}$ corrected. Trace 15 of 10/24/72.

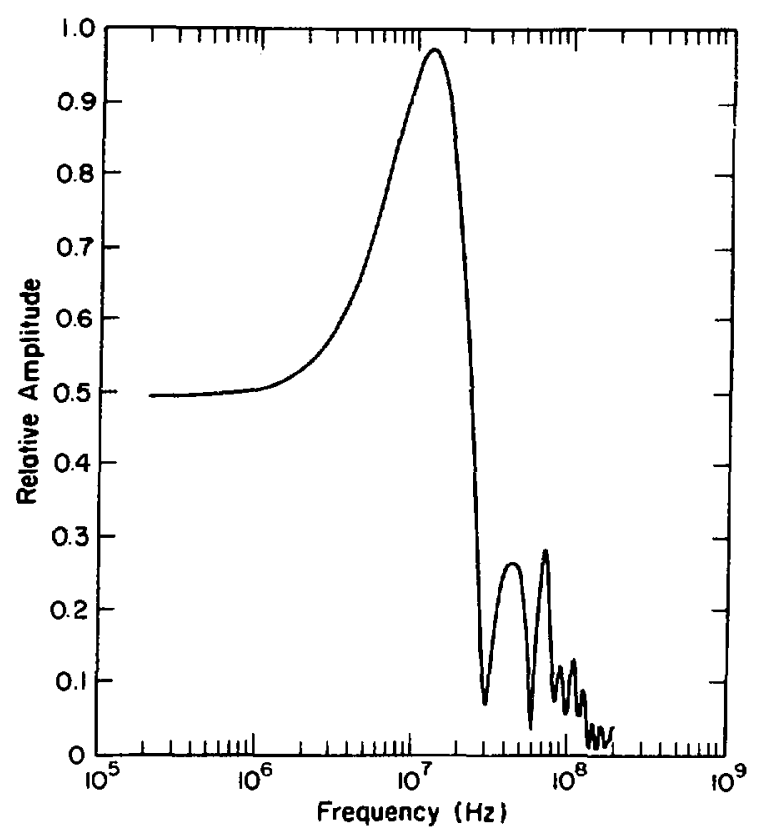

Fig. 20.

Sphere minus BA sensor. Trace 15 of 10/24/72. 


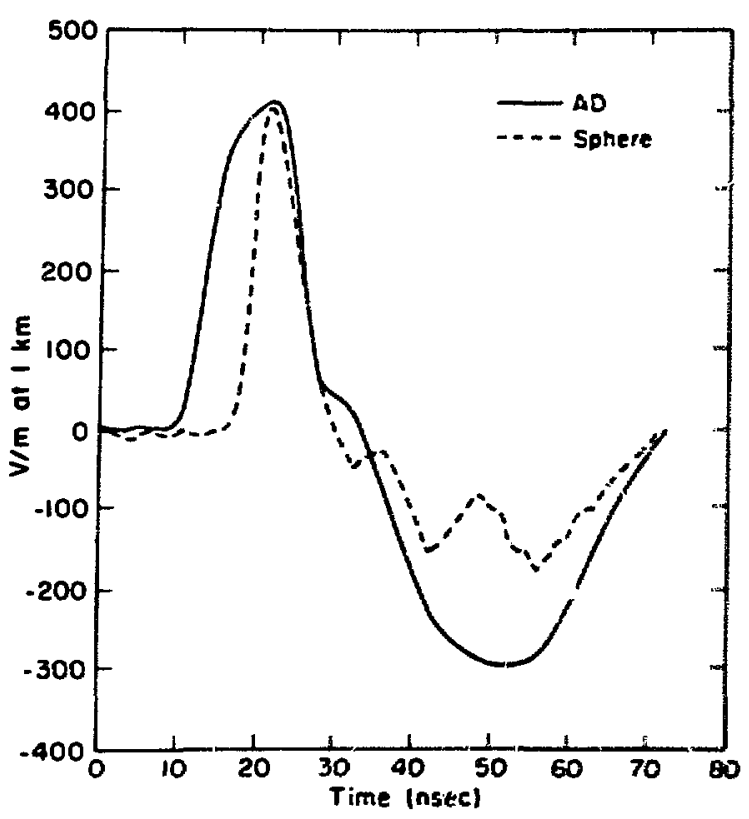

Fig. 21

Spbere and $A D$ sensors, lobe and Ef corrected. Trace 15 of 10/24/72.

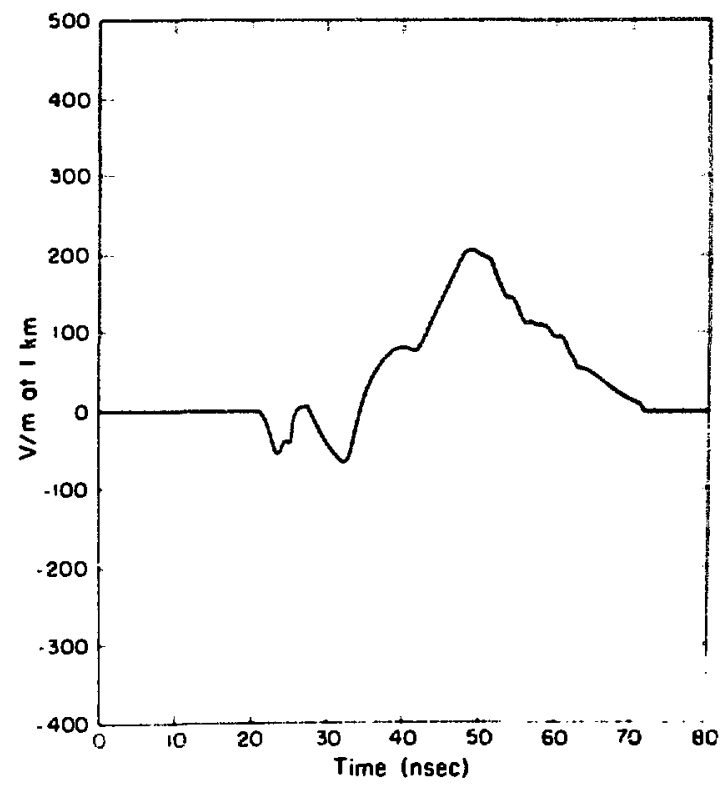

Fig. 22.

Spbere minus $A D$ sensor, lobe and $E_{f}$ corrected. Trace 15 of 10/24/72.

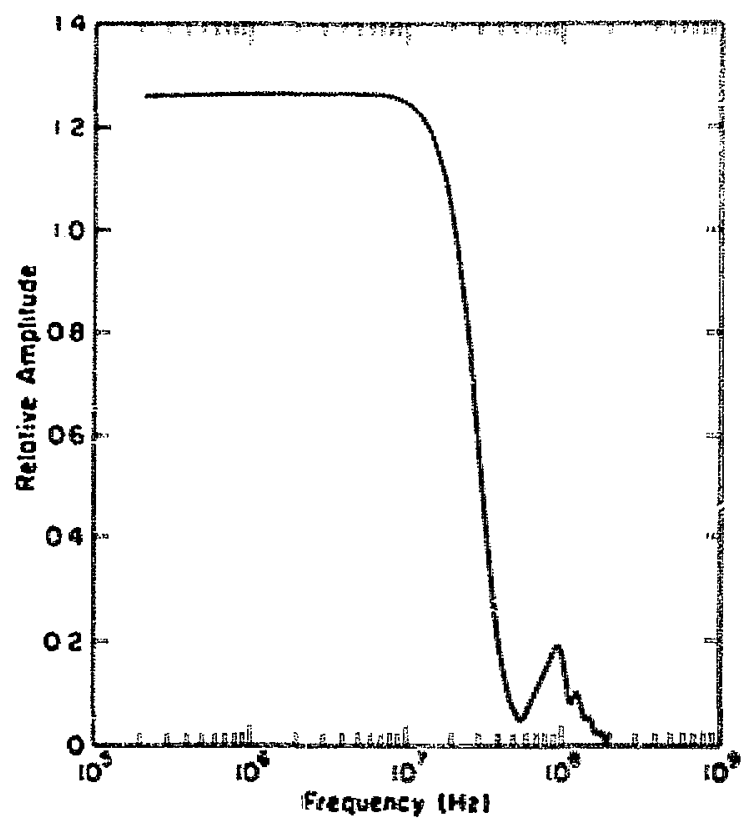

Fi. 23

Spbere minus AD sansor, lobe and to comecad. Trace is of $10 / 24 / 72$.

calculate precisely the if for an EMP sencor on the aircraft. It is believed that the $E_{f}$ can be mexsured vo about $\pm 5 \%$ under carefully controlled conditions bow. ever.

The required conditions for presise mewsurement of $E_{t}$ are as follows:

1. Aircraft position, heading. pitch, roll, atd atwitude must be automatically recorded every 5 we using the tiest available means, at least for three readings before and after the acrual pulse.

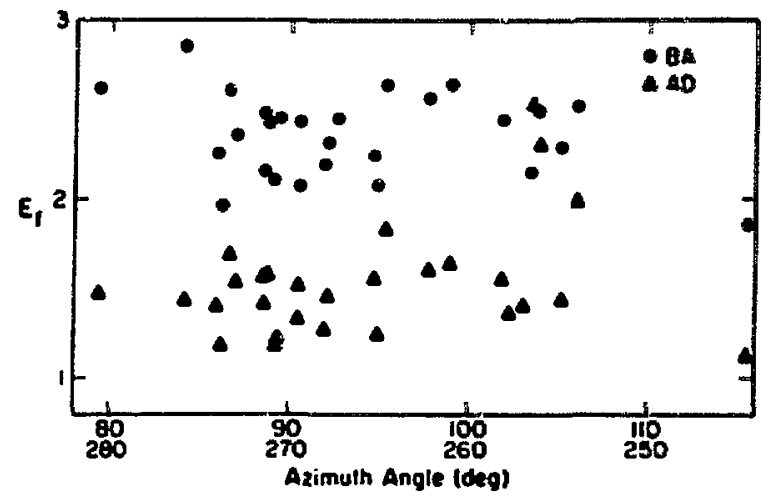

Fig. 24

$E_{f}$ os azinutb. 


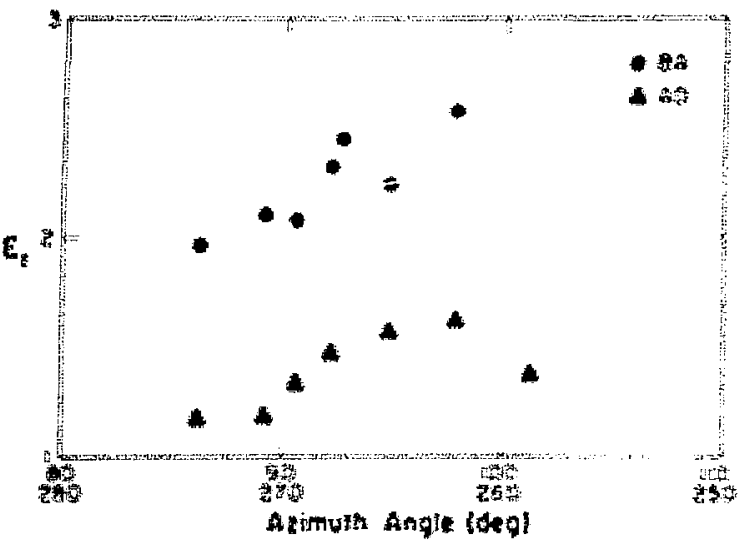

ftis. 25

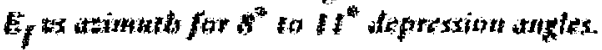

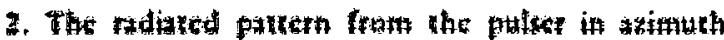

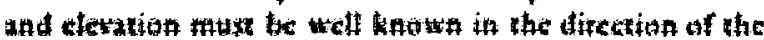
aireralt at putse time.

3. Cosein measuraments must be mate at $\$$ lotanion

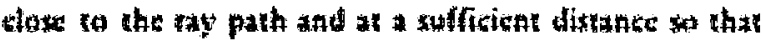
there is firle of no elfect ow the induetite or stutit

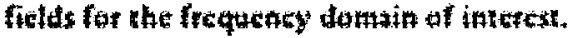

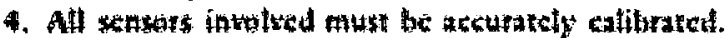

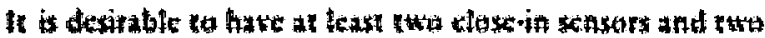
independent wetimss foll cath dirtraft antenth. bath air. craft system must have a camplete calibration as installet.

5. Serefal pulses hutd be taken under almost identi. cal conditions for a good watistical aterate.

6. Na pulses should be taken (or uxed) when the ray pxth from the sirealt to the purce pastes within $\$ 11 / 2^{\circ}$ from the wing tip (trailing edge or trading ede) for an individual ankenna because fo changes rapidy ih this region.

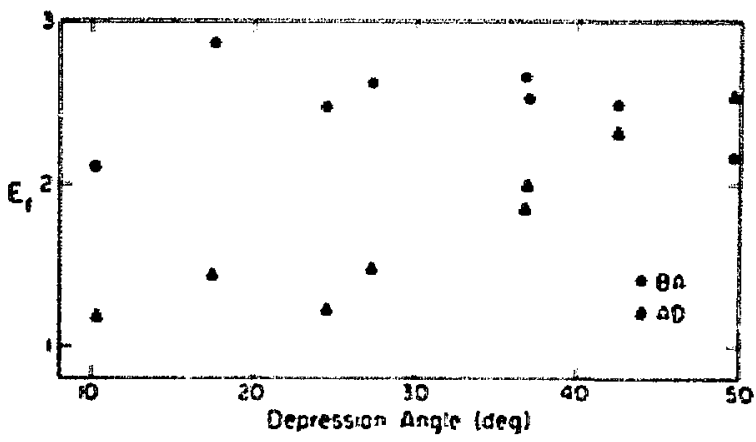

Pijg. 26

Ef us depression angle.

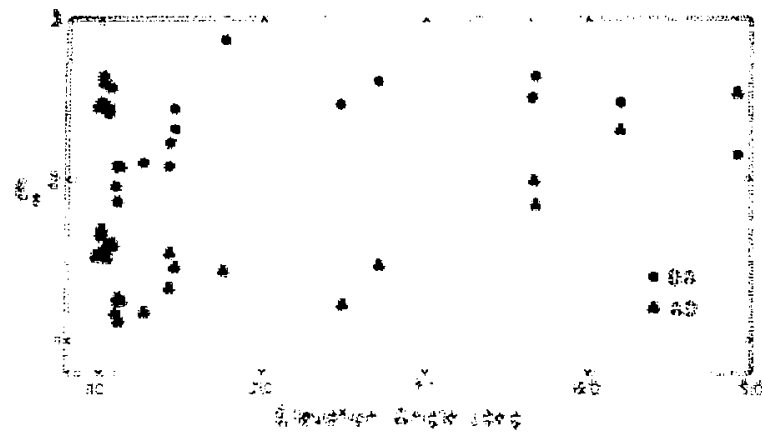

Fig. 27

Fif elewation angte.

\section{NCKNOWLEDCENENTS}

The authors wish to athoutlede the stpport of the afencics and personnd intotred in this experiment. We

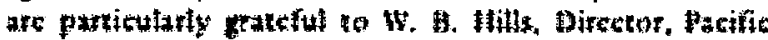

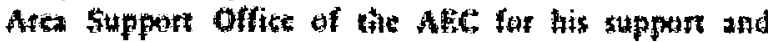
intistanee in the construction and operation of the simuta.

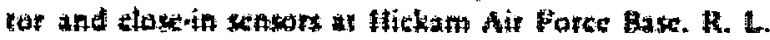

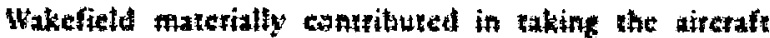
data and assisted in the pecparation of the Aighe glans. R. E. Partridge of LASt. was very helpful in the contartetion

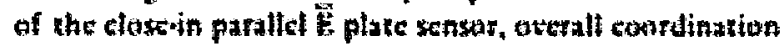
of ground artititics duriag the experiment, and in the senear eatibration. We afe gratefal also fer the contribuvions frow many people from the Sandia Laboratories.

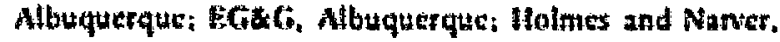
Itonglulu: the Air frorec crew which new the difficult Might plans; and the suppore personnel from leASt and DRE.

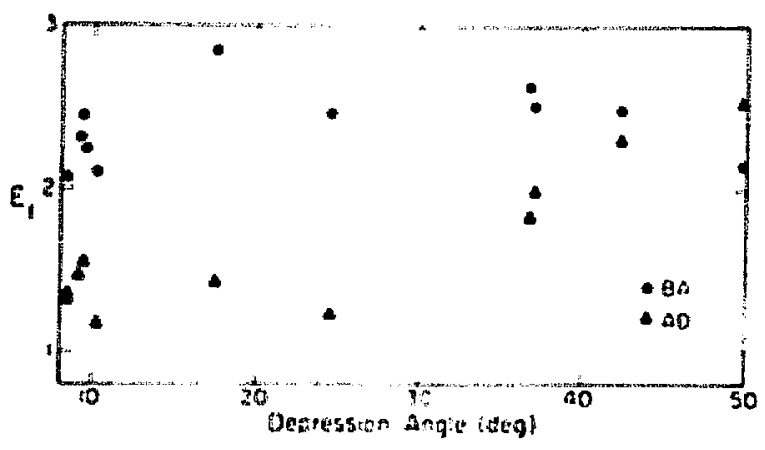

Pig. 28

ff us depression angle for $t^{\circ}$ forward to $26^{\circ}$ aft of beam. 
TABLE I

ENHANCEMENT FACTOR WITH RESPECT TO AZIMUTH AND DEPRESSION ANGLE FROM THE AIRCRAFT TO THE SOURCE

\begin{tabular}{|c|c|c|c|c|c|}
\hline \multirow[b]{2}{*}{ Date } & \multirow[b]{2}{*}{ Pulse No. } & \multirow{2}{*}{$\begin{array}{c}\text { Aximuth } \\
\text { (deg) }\end{array}$} & \multirow{2}{*}{$\begin{array}{c}\text { Depression } \\
\text { (deg) }\end{array}$} & \multicolumn{2}{|c|}{$\begin{array}{c}\text { Enhance- } \\
\text { ment } \\
\text { Factor }\end{array}$} \\
\hline & & & & $\overline{\mathbf{B A}}$ & $\overline{\mathbf{A D}}$ \\
\hline \multirow[t]{16}{*}{$10 / 24$} & 10 & 90.5 & 8.4 & 2.1 & 1.3 \\
\hline & 11 & 92.2 & 9.1 & 2.3 & 1.5 \\
\hline & 12 & 92.7 & 9.3 & 2.5 & \\
\hline & 13 & 94.8 & 9.4 & 2.2 & 1.6 \\
\hline & 14 & 273.8 & 8.0 & 2.0 & 1.2 \\
\hline & 15 & 268.0 & 6.1 & 2.1 & 1.3 \\
\hline & $\$ 6$ & 265.1 & 5.9 & 2.1 & 1.2 \\
\hline & 17 & 244.4 & 5.9 & 1.9 & 1.1 \\
\hline & 18 & 106.1 & 37.1 & 2.5 & 2.0 \\
\hline & 19 & 270.7 & 24.5 & 2.5 & 1.2 \\
\hline & 20 & 103.5 & 49.7 & 2.2 & 2.5 \\
\hline & 21 & 103.9 & 42.5 & 2.5 & 2.3 \\
\hline & 22 & 95.4 & 36.8 & 2.7 & 1.8 \\
\hline & 23 & 275.8 & 17.5 & 2.9 & 1.4 \\
\hline & 24 & 79.3 & 27.3 & 2.6 & 1.5 \\
\hline & 25 & 270.8 & 10.3 & 2.1 & 1.2 \\
\hline \multirow[t]{13}{*}{$10 / 26$} & 3 & 102.3 & 8.1 & & 1.4 \\
\hline & 4 & 103.1 & 4.8 & & 1.4 \\
\hline & 5 & 88.6 & -0.6 & 2.2 & 1.4 \\
\hline & 6 & 86.0 & 7.4 & 2.3 & 1.4 \\
\hline & 7 & 87.1 & 3.2 & 2.4 & 1.5 \\
\hline & $B$ & 88.6 & 6.9 & 2.5 & 1.6 \\
\hline & 9 & 88.8 & 7.4 & 2.4 & 1.6 \\
\hline & 10 & 90.5 & 7.3 & 2.4 & 1.5 \\
\hline & 11 & 97.9 & 8.2 & 2.6 & 1.6 \\
\hline & 12 & 99.0 & 7.1 & 2.7 & 1.6 \\
\hline & 13 & 101.9 & 7.1 & 2.5 & 1.5 \\
\hline & 14 & 105.3 & 6.8 & 2.3 & 1.4 \\
\hline & 17 & 86.7 & -3.5 & 2.6 & 1.7 \\
\hline
\end{tabular}

\section{REFERENCES}

I. C. U. Benton, R. L. Wakefield, E. D. Niper, and R. L. Schellenbaum, "EMP in the Ionosphere" Los Alemos Scientific Laboratory, report LA-4947 (September 1972).

2. H. M. Peck and K. N. Joy, "Operation Picaposte," Los Alamos Scientific Laboratory Internal Document (September 1972).

3. R. W. Buchanan, System Response and Propagation Studies, Unizersity of Denver, Denver Research Institute, report DRI \#613 (December 1972)

4. R. F. Harrington, Time Harmonic Electromagnetic Fields, McGraw-Hill, p.294, (1961).

S. R. C. Singleton. "On Computing the Fast Fourier Transform," Comm, ACM, Vol. 10, 1967, pp. 647-654.

6. R. J. Lycle and D. L. Lager, Electromagnetic Propagation Transmission, Reflection, and Refraction: Equations and Numerical Results, Lawrence Livermore Laboratory, report UCRL-51245 (June 1972).

7. R. R. Lentz, P. H. Pathok, and W. D. Burnside, The Ohio State Universiry Elecrroscience Laboratory, Interaction Notes, Note 117 (June 1972).

8. D. M. Levine, Propagation Delay in the Atmosphere, NASA report NASA-TM-X-65460 (November 1970). 